\title{
PENGOLAHAN AIR SUMUR DENGAN FILTER SISTEM BACKWASH DI KELURAHAN MARIANA KECAMATAN BANYUASIN I
}

\author{
Muhrinsyah Fatimura $^{1)}$, Muhammmad Bakrie ${ }^{2)}$, Agus Wahyudi' ${ }^{3)}$, Aan Safentry ${ }^{4)}$ \\ Teknik Kimia, Fakultas Teknik, Universitas PGRI Palembang
}

\begin{abstract}
Abstrak
Air merupakan sumber kehidupan terdiri dari senyawa kimia yang sangat penting bagi kehidupan makhluk hidup di bumi ini. Pemanfaatan air sebagai kebutuhan pokok bagi manusia dengan segala macam kegiatannya, antara lain digunakan untuk: keperluan rumah tangga, misalnya untuk minum, masak, mandi, cuci dan segala kegiatan yang menggunakan air lainnya. Adanya keluhan dari warga Perum Griya Mariana Rt.07 Rw.02 Kelurahan Mariana Kecamatan Banyuasin I Kabupaten Banyuasin akan mutu air yang digunakan sehari-hari yang berasal dari sumur warga, dimana air digunakan untuk mandi terasa lengket dan kalau ditampung di bak penampungan air berubah warna menjadi kemerahan kadang kehitaman serta terasa asam . Hasil analisis awal yang dilakukan dilaboratorium sebelum menggunakan peralatan yang dibuat yaitu: $\mathrm{pH} 3, \mathrm{Fe} \mathrm{5,98mg/l,} \mathrm{kekeruhan} 20 \mathrm{Ntu}$, berbau kondisi ini tidak memenuhi standar air baku mutu kadar maksimun. Berdasarkan Peraturan Menteri Kesehatan Republik Indonesia Nomor.32 Tahun 2017. Perancangan peralatan filtrasi dengan sistem backwash diharapkan dapat mengatasi masalah yang ada. Masyarakat sangat antusias saat pelaksanaan pengabdian masyarakat ini terbukti banyaknya pertanyaan yang diberikan warga pada pemateri dan pada saat pengoperasian peralatan back wash. Hasil pengoperasian filter back wash didapat setelah di analis $\mathrm{pH}$ 6,5 , Fe 0,6 mg/l, kekeruhan $3 \mathrm{Ntu}$, dan tidak bebau. Peralatan ini dapat meningkatkan mutu air baku yaitu air sumur masyarakat.
\end{abstract}

Kata Kunci: air, filter, back wash

\begin{abstract}
Water is a source of life consisting of chemical compounds that are very important for the life of living things on this earth. The use of water as a basic need for humans with all kinds of activities, among others, is used for: household needs, for example for drinking, cooking, bathing, washing and all activities that use other water. There are complaints from residents of Mariana Rt.07 Rw.02 Perum Mariana Village, Banyuasin I Subdistrict, Banyuasin Regency, about the quality of water used daily from community wells, where the water used for bathing is sticky and changes color it becomes reddish sometimes blackish and feels sour. The results of the initial analysis carried out at the laboratory before using the equipment made were: $\mathrm{pH}$ 3, Fe 5.98mg / l, turbidity $20 \mathrm{Ntu}$, smelling this condition did not meet the maximum standard water quality standards. Based on the Regulation of the Minister of Health of the Republic of Indonesia Number 32 Year 2017. The design of filtration equipment with a backwash system is expected to overcome the existing problems. The community was very enthusiastic when the implementation of community service proved that there were many questions that were given by residents to the speakers and during the operation of back wash equipment. The results of the operation of the back wash filter were obtained after the analyst $\mathrm{pH} 6.5, \mathrm{Fe} 0.6 \mathrm{mg} / \mathrm{l}$, turbidity $3 \mathrm{Ntu}$, and not ignored. This equipment can improve the quality of raw water, namely community well water.
\end{abstract}

Key words: Water, Filter, Back wash

Correspondence author: Muhrinsyah Fatimura, muhrinsyah.f@gmail.com, Indonesia

This work is licensed under a CC-BY-NC 


\section{PENDAHULUAN}

Air merupakan senyawa kimia yang merupakan sumber kehidupan dimana terdiri dari senyawa kimia yang sangat diperlukan bagi kehidupan makhluk hidup di bumi ini. Fungsi air bagi kehidupan tidak dapat digantikan oleh senyawa lain. Pemanfaatan air sebagai kebutuhan pokok bagi manusia dengan segala macam kegiatannya, antara lain digunakan untuk keperluan rumah tangga, misalnya untuk minum, masak, mandi, cuci dan pekerjaan lainnya. Untuk memenuhi kebutuhan air bersih umumnya di Propinsi Sumatra Selatan belum sepenuhnya dapat disuplai oleh Perusahaan Daerah Air Minum setempat terutama untuk penduduk yang berdomisili di pedesaan dan di pinggiran kota yang sebagian besar mengandalkan air sungai dan air sumur untuk keperluan air bersih.

Adanya keluhan dari salah satu warga perum griya mariana akan air yang digunakan yang berasal dari sumur warga apabila air digunakan untuk mandi terasa lengket dan kalau ditampung di bak penampungan air berubah warna menjadi kemerahan kadang kehitaman serta terasa asam. Masyarakat perum griya mariana sudah berusaha untuk menghilangkan kekeruhan air dengan cara membuat saringan pasir lambat dengan menggunakan drum yang diisi pasir ,koral dan ijok . Hasil yang didapat kekeruhan bisa mereka atasi tetapi air akan berubah menjadi kemerahan ketika di endapkan beberapa saat dan apabila digunakan untuk mencuci ketika di campur dengan ditergen air berubah menjadi kehitaman serta pada saat pembersihan saringan pasir yang mereka buat susah untuk di bersihkan karena harus dibongkar satu-satu media didalam drum. Keluhan yang di alami oleh masyarakat ini langsung tim dari program studi teknik kimia terjun kelapangan untuk mengambil sampel atas keluhan masyarakat tersebut. Dan hasil uji laboratorium didapat untuk $\mathrm{pH} 3$, Fe 5,98 mg/l , kekeruhan $20 \mathrm{Ntu}$, bau berbau kondisi ini tidak memenuhi Standar Air Baku Mutu Kadar Maksimun Berdasarkan Peraturan Menteri Kesehatan Republik Indonesia Nomor.32 Tahun 2017.

Beberapa penelitian untuk mengurangi kadar besi dalam air Penurunan kadar besi (Fe) setelah perlakuan Aerasi dapat menurunkan kadar besi ( $\mathrm{Fe}$ ) hingga mencapai persentase Penurunan sebesar 66,7\% ( rasaman,2016). Air sumur daerah Dukuh Setro Rawasan Surabaya. Analisis Fe menggunakan metode Ortho-Phenantrolin secara Spektrofotometri, sedangkan analisis Mn menggunakan metode Persulfat. Setelah ditreatment, untuk media Zeolit efisiensi penurunan paling optimum terjadi pada debit 1 L/menit, dimana untuk Fe sebesar $57.13 \%$ dan Mn sebesar 70.00\%. Sedangkan media Manganese Greensand, efisiensi penurunan paling optimum juga terjadi pada debit 1 1/menit, dimana untuk Fe sebesar 78.36\% dan Mn sebesar 88.21\% ( Nastiti,2017). Treatment ferrolite, manganese zeolite, dan ion exchanger berupa resin anion dan resin kation pada air tanah mampu meremoval kandungan beban kekeruhan, warna, dan logam logam Besi, Kromium, serta Mangan hingga menjadi kriteria parameter air bersih mengacu pada permenkes nomor 416 / Menkes / Per / IX /1990.

Untuk itulah perlu dilakukan masukkan untuk menyelesaikan masalah yang terjadi pada masyarakat di perumahan griya mariana dari dosen teknik kimia fakultas teknik universitas PGRI Palembang. Adapun tujuan pengabdian pada masyarakat yaitu memberikan penyuluhan kepada masyarakat tentang air bersih, membimbing dan mengarahkan masyarakat dalam mengelola dan memanfaatkan sumber air yang ada, mengatasi permasalahan air yang ada dilingkungan perumahan griya mariana RT.07 RW.02 kelurahan mariana kecamatan banyuasin kabupaten banyuasin dengan merancang alat yang bisa mengatasi permasalahan air yang warga hadapi selama ini. 


\section{METODE PELAKSANAAN}

Pelaksanaan kegiatan pengabdian pada masyarakat yang diadakan Program Studi Teknik Kimia dilaksanakan pada 11 Agustus 2018 yang bertempat di Perumahan Griya Mariana RT 07 RW 02 Kelurahan Mariana Kecamatan Banyuasin I Kabupaten Banyuasin Sumatera Selatan.

Dalam pelaksanaannya program studi teknik kimia mengundang masyarakat di sekitar perumahan griya mariana pada salah satu rumah warga tempat pusat kegiatannya. Pelaksanaan pengabdian pada masyarakat dilaksanakan dengan metode ceramah dan pembuatan alat filter air dengan sistem back wash secara langsung kepada masyarakat Perumahan Griya Mariana Permai Rt.07 Rw.02 Kelurahan Mariana Kecamatan Banyuasin I Kabupaten Banyuasin.

Pelaksanaan PKM ini didahuli dengan survey awal kelapangan dengan cara mengambil sampel air baku yaitu air sumur yang kemudian di analisis di laboratorium sebagai berikut :

Tabel .1 Hasil Analisis Awal Air Baku (Sumur) :

\begin{tabular}{ccc}
\hline Parameter & $\begin{array}{c}\text { Air Baku } \\
\text { (Air Sumur Griya Mariana) } \\
\text { Tanggal 8 Agustus 2018 }\end{array}$ & $\begin{array}{c}\text { Standar Air Baku Mutu } \\
\text { Kadar Maksimun }\end{array}$ \\
Parameter Kimia & & \\
\hline $\mathrm{pH}$ & 3 & $6.5-8.5$ \\
\hline Besi (Fe) & $5,98 \mathrm{mg} / 1$ & $1 \mathrm{mg} / \mathrm{l}$ \\
\hline Parameter Fisika & & $5 \mathrm{NTU}$ \\
\hline Kekeruhan & 20 NTU & Tidak Berbau \\
\hline Bau & Agak Berbau & \\
\hline
\end{tabular}

Dari tabel 1. hasil analisis awal di dapat untuk parameter $\mathrm{pH}$, Besi (Fe) ,kekeruhan serta bau masih di atas standar air baku mutu kadar maksimum yang ditetapkan Menteri Kesehatan Republik Indonesia Nomor 32 Tahun 2017 .

Program studi teknik kimia memberikan solusi dengan cara membuat rancangan alat filtrasi dengan sistem back wash. Adapun peralatan yang diperlukan untuk merancang peralatan filtrasi ini adalah : Pipa PVC 4 inchi panjang $150 \mathrm{~cm}$, Tee, elbow ,pipa $1 / 2$ inchi, valve $1 / 2$ inchi, tutup paralon 4 inchi berulir, dop 4 inchi. Media filtrasi yang di gunakan pada perancangan alat filtrasi ini yaitu: Pasir silika, Batu koral kecil dan besar,karbon aktif, ferrolite .

Merancang peralatan filtrasi dengan sistem backwash seperti pada gambar 1. Setelah di rangkai kemudian baru di masukkan media filtrasi dimana susunan dari media dari atas kebawah adalah sebagai berikut pasir silika setinggi $25 \mathrm{~cm}$,karbon aktif setinggi $20 \mathrm{~cm}$, Koral besar dan kecil setinggi $20 \mathrm{~cm}$ serta pada bagian bawah di isi dengan ferrolite setinggi $40 \mathrm{~cm}$.

Setelah itu melakukan operasi filtrasi, filter penjernih air selesai kita buat dan siap dioperasikan Prinsip kerja Filter yang kita buat : ada 2 sistem kerja filtrasi pertama proses penyaringan (filtrasi), kedua pencucian (backwash). 


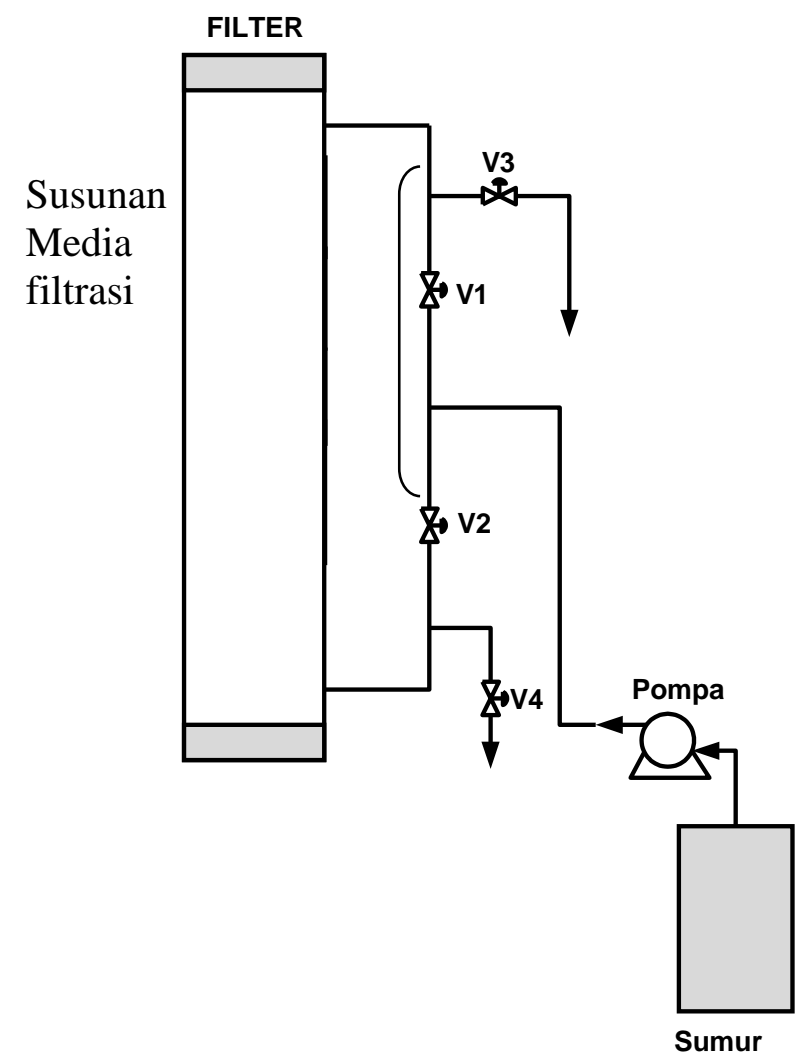

Gambar 1. Diagram Alir Rancangan Alat Filtrasi Dengan Sistem Back Wash.

Keterangan cara pengoperasi filter sistem back wash gambar 1:

$\begin{array}{lll}\text { Proses Filtrasi (Penyaringan) } & \text { V1,V4 } & \text { Dibuka } \\ & \text { V2,V3 } & \text { Ditutup } \\ \text { Proses Backwash (Pencucian) } & \text { V1,V4 } & \text { Ditutup } \\ & \text { V2,V3 } & \text { Dibuka }\end{array}$

\section{HASIL DAN PEMBAHASAN}

Tabel 2 Hasil analisis air baku (sumur) yang telah melalui proses filtrasi melewati media filter dan penambahan $\mathrm{CaCO}_{3}$ di dalam sumur adalah sebagai berikut:

\begin{tabular}{|c|c|c|}
\hline Parameter & $\begin{array}{c}\text { Air sumur yang telah melalui alat filtrasi } \\
\text { (Air Sumur Griya Mariana) Tanggal } 11 \\
\text { Agustus } 2018\end{array}$ & $\begin{array}{l}\text { Standar Air Baku Mutu } \\
\text { Kadar Maksimun } \\
\text { Berdasarkan Peraturan Menteri Kesehatan } \\
\text { Republik Indonesia Nomor 32 Tahun 2017. }\end{array}$ \\
\hline \multicolumn{3}{|l|}{ Parameter Kimia } \\
\hline $\mathbf{p H}$ & 6.5 & $6.5-8.5$ \\
\hline Besi $(\mathrm{Fe})$ & $0.6 \mathrm{mg} / \mathrm{l}$ & $1 \mathrm{mg} / \mathrm{l}$ \\
\hline \multicolumn{3}{|l|}{ Parameter Fisika } \\
\hline Kekeruhan & 3 NTU & 5 NTU \\
\hline Bau & Tidak Berbau & Tidak Berbau \\
\hline
\end{tabular}


Dari hasil analisis di dapat untuk parameter $\mathrm{pH}$, Besi (Fe), kekeruhan serta bau masih di bawah standar air baku mutu kadar maksimum yang ditetapkan Menteri Kesehatan Republik Indonesia Nomor 32 Tahun 2017 • pH dari 3 yang bersifat asam bisa di naikkan menjadi pH 6.5 ini dengan menaburkan bubuk $\mathrm{CaCO}_{3}$ ( kapur) yang banyak di jual di toko bangunan sehingga mudah di dapat oleh masyarakat di sekitar. Penambahan kapur batu gamping dihasilkan suhu rata-rata sebesar $29,57^{\circ} \mathrm{C}$, menaikkan dari pH 6.17 menjadi pH 8,36 (Ulfi.2011). Kekeruhan yang semula 20 NTU berkurang menjadi 3 NTU, sedangkan kadar besi yang semula $5,98 \mathrm{mg} / \mathrm{l}$ menjadi $0.65 \mathrm{mg} / \mathrm{l}$.

Pada warga masyarakat yang dirasakan langsung setelah melalui pengolahan ini. Air yang keluar dari filtrasi pada saat digunakan untuk mencuci dicampur dengan ditergent air tidak berubah lagi menjadi kehitam-hitaman yang selama ini di keluhkan oleh masyarakat perum griya mariana permai kemudian alat filtrasi mudah untuk di bersihkan karena dengan sistem back wash tinggal memutar valve pencucian filter mencuci dengan mudah tanpa harus membuka saringan yang selama ini dilakukan oleh masyarakat. Filtrasi digunakan untuk menurunkan kekeruhan dan kadar Fe dengan memanfaatkan media kerikil, pasir kwarsa dan karbon aktif (Usman, 2014). Sistem aerasi tray-sedimentasi-filtrasi efektif menurunkan kekeruhan dan tingkat zat besi pada air tanah (Irfan, 2016).

(a)

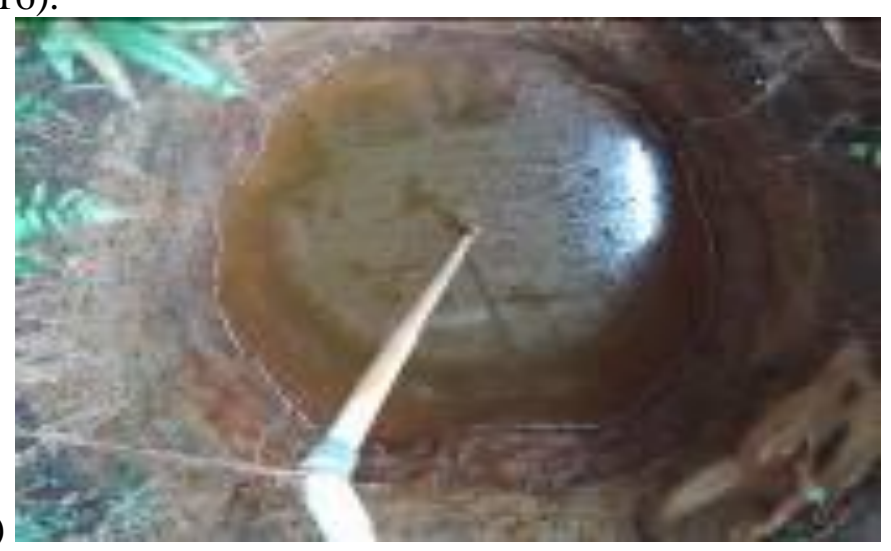

(b)

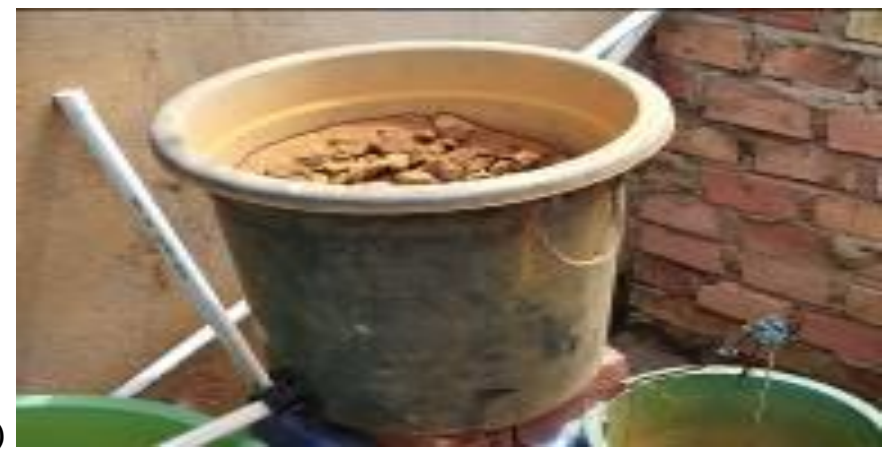




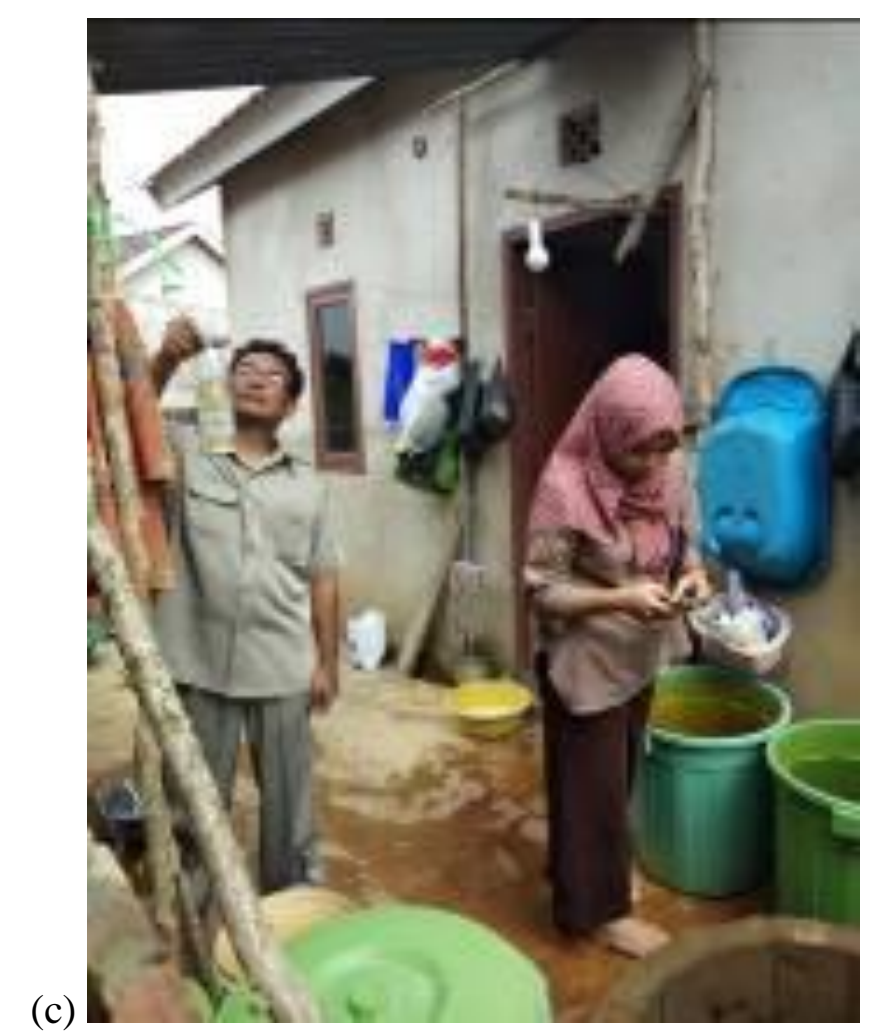

Gambar 2. Kondisi air sebelum di lakukan filtrasi a.Kondisi air sumur b.Filter pasir yang dibuat oleh masyarakat c.tim mengambil sampel

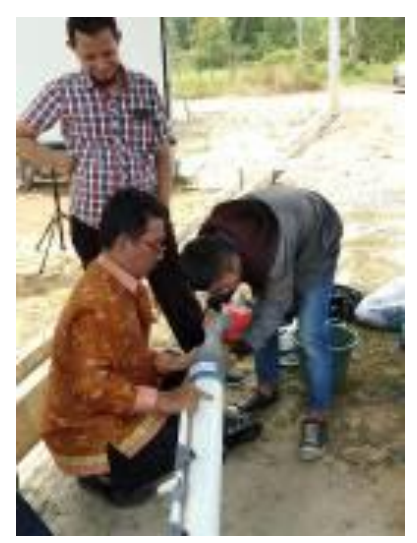

(a)

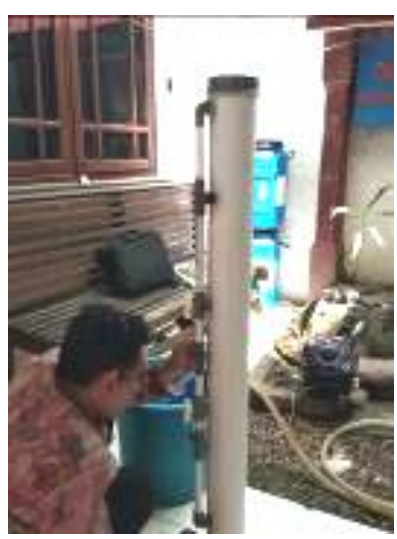

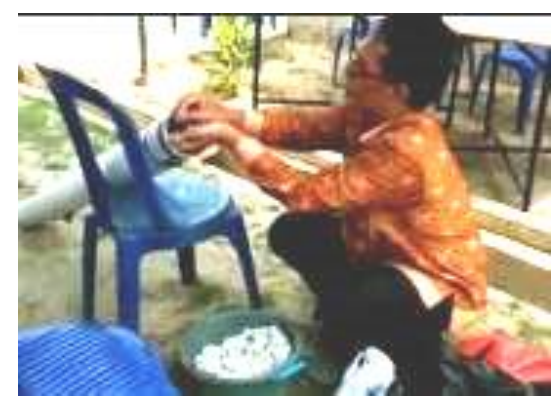

(b)

Gambar 3. (a).Instalasi Peralatan Filtrasi Sistem Back wash (b).pengisian media.

Pada pelaksanaan pengujian filter dengan sistem back wash di rancang untuk mempermudah masyarakat griya mariana permai dalam penggunaannya

Pada gambar.1 alir rancangan alat filtrasi dengan sistem back wash diagram proses dalam pengoperasian untuk proses penyaringan posisi valve V1,V4 dibuka dan posisi valve V2,V3 ditutup dan untuk melakukan pencucian filter apabila sudah dalam keadaan kotor dengan mengoperasikan filter ke proses pencucian ( back wash) dengan memutar valve V1,V4 diposisi tutup dan valve V2,V3 diposisi buka. 


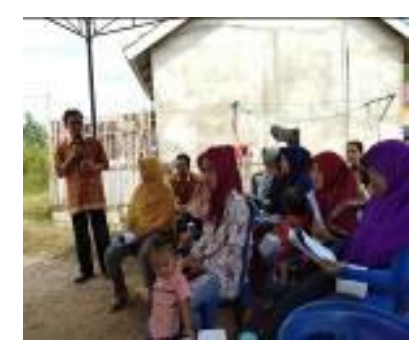

(a)

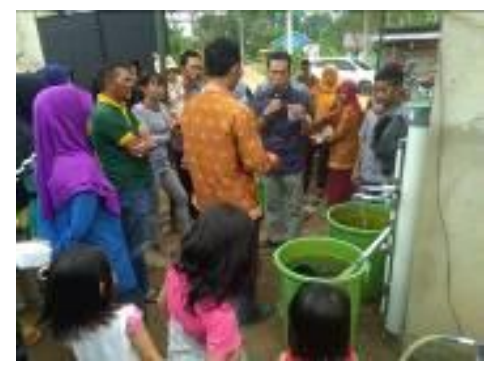

(c)

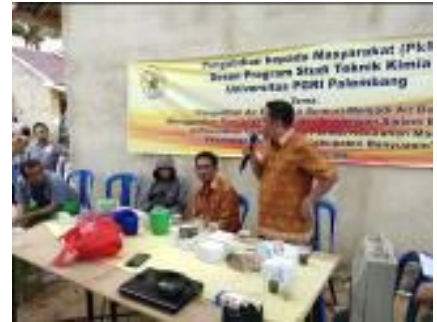

(b)

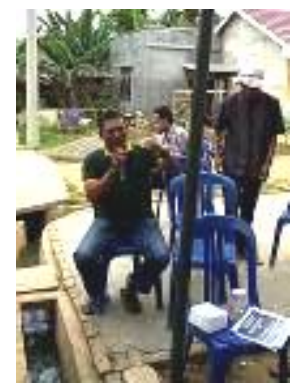

(d)

Gambar 4. (a,b,c) Penyuluhan yang di bawakan beberapa pemateri tentang pengolahan air bersih serta cara pengoperasian alat filtrasi (d) tanya jawab dengan warga masyarakat.

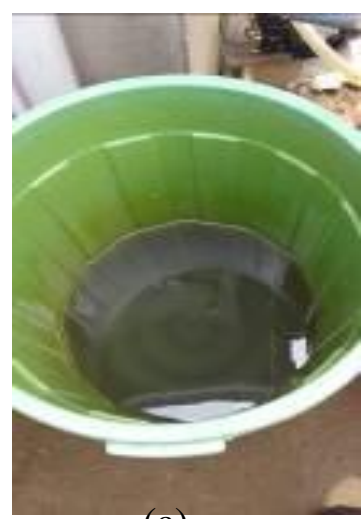

(a)

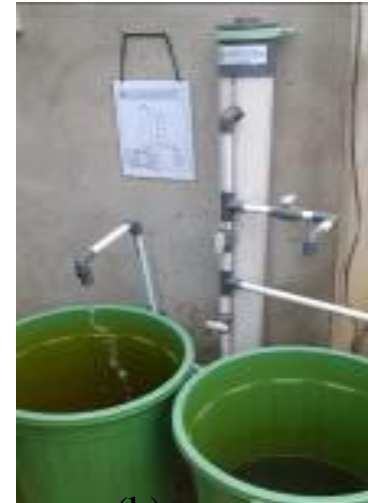

(b)

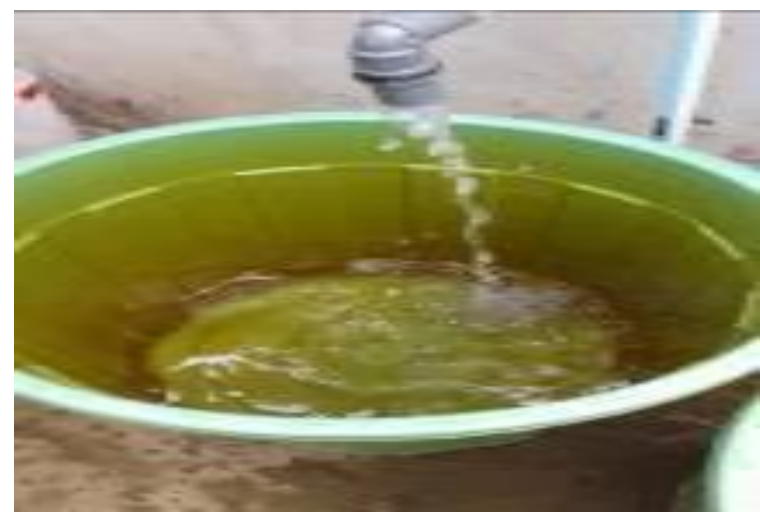

(c)

Gambar 5. Hasil Pengoperasian (a) air sumur (b) filtrasi sedang beroperasi (c) air yang sudah melalui filtrasi. 
Hasil rancangan alat filtrasi dengan sistem back wash yang di buat oleh tim program studi teknik kimia universitas pgri Palembang di sumbangkan kepada warga untuk menjadi percontohan dan antusias warga untuk menyelesaikan masalah air yang mereka alami selama ini mendapat solusi dan masyarakat mengharapkan untuk terus dapat berkonsultasi agar masing-masing warga dapat membuat peralatan filtrasi ini pada masing-masing rumah mereka.

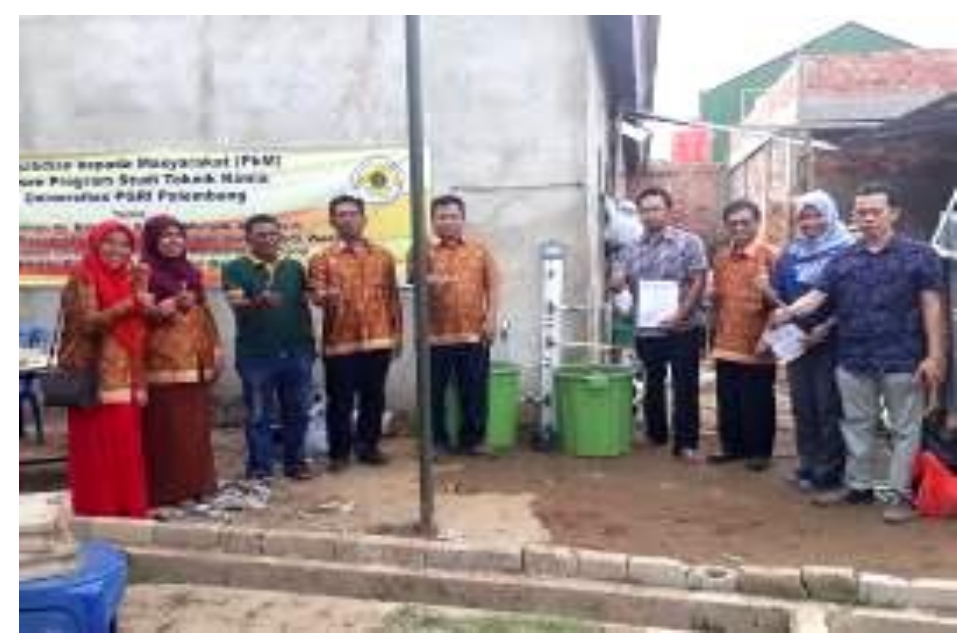

Gambar 6. Alat filtrasi diserahkan kepada masyarakat Perumahan Griya Mariana Permai

\section{SIMPULAN}

Kegiatan Pengabdian Kepada Masyarakat yang dilaksanakan Program Studi Teknik Kimia berjalan dengan antusias ini terlihat banyaknya pertanyaan yang ditanyakan kepada Tim Prodi Teknik Kimia Universitas PGRI Palembang, masyarakat Griya Mariana Permai meminta agar dapat membimbing di waktu yang lain untuk dapat menjadi instruktur dalam pembuatan alat Filter Dengan sistem Back Wash . Permintaan warga ini di sambut dengan baik oleh Tim Prodi Teknik Kimia. Indikator ini menandakan bahwa kegiatan PKM ini sangat tepat dalam memberikan bantuan dalam menyelesaikan permasalahan air bersih yang terjadi dalam lingkungan perumahan griya mariana permai. Peralatan yang di rancang oleh Tim Prodi Teknik Kimia diberikan kepada masyarakat sebagai bantuan percontohan untuk masyarakat .Demikianlah semoga kegiatan PKM ini dapat memberikan manfaat pada masyarakat griya mariana permai dimana sebagai dosen merupakan bentuk Tri Dharma Perguruan Tinggi.

\section{DAFTAR PUSTAKA}

Choiriyah, U. (2001). Pengaruh Penambahan Kapur Batu Gamping $\left(\mathrm{CaCO}_{3}\right)$ Pada Proses Koagulasi Dengan Menggunakan Alumunium Sulfat $\left[\mathrm{Al}_{2}\left(\mathrm{SO}_{4}\right)_{3}\right]$ Dalam Menurunkan Kekeruhan Pada Ai Sungai Sayung Kabupaten Demak

Febiary, I., Widiyanto, A. F., \& Yuniarno, S. (2016). Efektivitas Aerasi, Sedimentasi, Dan Filtrasi Untuk Menurunkan Kekeruhan Dan Kadar Besi (Fe) Dalam Air. Kesmas Indonesia, 8(01), 32-39. 
Jenti, U. B., \& Nurhayati, I. (2014). Pengaruh Penggunaan Media Filtrasi terhadap Kualitas Air Sumur Gali Di Kelurahan Tambak Rejo Waru Kabupaten Sidoarjo. WAKTU, 12(2), 34-38.

Oesman, N. M., \& Sugito, S. (2017). Penurunan Logam Besi Dan Mangan Menggunakan Filtrasi Media Zeolit Dan Manganese Greensand. WAKTU, 15(2), 57-69.

Peraturan Menteri Kesehatan Republik Indonesia Standar Air Baku Mutu Kadar Maksimun Nomor 32 Tahun 2017.

Rasman, Muh Saleh.(2016). Penurunan Kadar Besi (Fe) dengan Sistem Aerasi dan Filtrasi Pada Air Sumur Gali (Eksperimen). Jurnal Higine Volume 2 No. 3. September-Desember 2016. 